\title{
AN EXTENSION OF THE DAVIS-GUT LAW AND LAI LAW
}

\section{YONG ZHANG}

Abstract. Let $\left\{X, X_{n}, n \geqslant 1\right\}$ be a sequence of i.i.d. random variables with $E X=0$ and $E X^{2}=1$ and the partial sums $S_{n}=\sum_{k=1}^{n} X_{k}, n \geqslant 1$. Assume that $f(x)$ and $g(x)$ are positive functions defined on $[0, \infty)$. In this short note, under some suitable conditions, we establish the following results

$$
\sum_{n=1}^{\infty} f(n) P\left\{\left|S_{n}\right|>\beta \sqrt{n} g(n)\right\}<\infty \text { or }=\infty
$$

according as

$$
\sum_{n=1}^{\infty} \frac{f(n)}{g(n)} \exp \left\{-\frac{\beta^{2}}{2} g^{2}(n)(1+\alpha(n))\right\}<\infty \text { or }=\infty
$$

where $\alpha(n)=E X^{2} I\{|X|>\sqrt{n} g(n)\} / E X^{2} I\{|X| \leqslant \sqrt{n} g(n)\}, \beta>0$. The results extend and generalize the known Davis-Gut Law and Lai Law.

Mathematics subject classification (2010): 60F15.

Keywords and phrases: Davis-Gut law, Lai law, nonuniform estimate.

\section{REFERENCES}

[1] P.Y CHEN, Y.C. QI, Generalized law of the iterated logarithm and lts convergence rate, Stochastic Analysis and Applications, 25, 1 (2007), 89-103.

[2] P.Y Chen, D.C. WANG, Convergence rates for probabilities of moderate deviations for moving average processes, Acta Mathematica Sinica, English Series, 24, 4 (2008), 611-622.

[3] J.A. DAVIS, Convergence rates for the law of the iterated logarithm, Annals of Mathematical Statistics, 39, 5 (1968), 1479-1485.

[4] A. GuT, Convergence rates for probabilities of moderate deviations for sums of random variables with multidimensional indices, Annals of Probability, 8, 2 (1980), 298-313.

[5] T.L. LAI, Limit theorems for delayed sums, Annals of Probability, 2, 3 (1974), 432-440.

[6] D.L. LI, Convergence rates for law of iterated logarithm for B-valued random variables, Science in China Ser A, 4, (1991), 395-404.

[7] D.L. Li, X.C. WANG, M.B. RAO, Some results on convergence rates for probabilities of moderate deviations for sums of random variables, International Journal of Mathematics and Mathematical Sciences, 15, 3 (1992), 131-149.

[8] D.L. Li, A. Rosalsky, A supplement to the Davis-Gut law, Journal of Mathematical Analysis and Applications, 330, 2 (2007), 1488-1493.

[9] X.D. LiU, H.Y. QiAn, L.Q. CAO, The Davis-Gut law for moving average processes, Statistics and Probability Letters, 104, (2015), 1-6.

[10] X.D. LiU, H. Guo, A note on the Davis-Gut law, Statistics and Probability Letters, 105, 3 (2015), $163-167$.

[11] X.D. Liu, J. Meng, The Davis-Gut law and Lai law for finitely inhomogeneous walks, Journal of Mathematical inequalities, 11, 1 (2017), 281-289.

[12] S. V. NAGAEv, Some limit theorems for large deviations, Theory of Probability and Its Applications, 10, (1965), 231-254. 